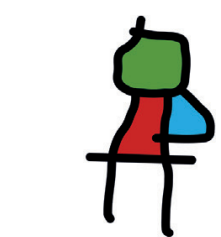

SEICAIP

\section{Allergologia et immunopathologia}

Sociedad Española de Inmunología Clínica, Alergología y Asma Pediátrica

wWw.all-imm.com

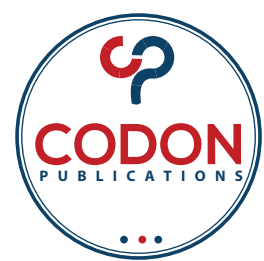

ORIGINAL ARTICLE

OPEN ACCESS CC)(1) (2)

\title{
The association between seropositivity to human toxocariasis and childhood asthma in northern Iran: a case-control study
}

\author{
Sorena Darvisha, Iraj Mohammadzadeh ${ }^{\mathrm{b}}$, Saeed Mehravarc, Adel Spotin ${ }^{\mathrm{d}, \mathrm{e}}$, Ali Rostami*
}

\author{
aStudent Research Committee, Babol University of Medical Sciences, Babol, Iran \\ ${ }^{b}$ Non-Communicable Pediatric Diseases Research Center, Health Research Institute, Babol University of Medical Sciences, \\ Babol, Iran \\ 'Department of Epidemiology and Biostatistics, School of Public Health, Tehran University of Medical Science, Tehran, Iran \\ IImmunology Research Center, Tabriz University of Medical Sciences, Tabriz, Iran \\ eStudent Research Committee, Tabriz University of Medical Sciences, Tabriz, Iran \\ fInfectious Diseases and Tropical Medicine Research Center, Health Research Institute, Babol University of Medical Sciences, \\ Babol, Iran
}

Received 3 May 2020; Accepted 7 October 2020

Available online 2 January 2021

\section{KEYWORDS}

Toxocara infection; association; childhood asthma; ELISA; Iran

\begin{abstract}
Background: Besides the well-known risk factors, Toxocara infection is thought to play a significant etiological role in the development of childhood asthma. To further explore this association, the prevalence of Toxocara infection in sera of asthmatic children and healthy controls in northern Iran was investigated.

Methods: In this case-control study, cases were 145 physician-confirmed asthmatic children diagnosed according to the Global Initiative for Asthma (GINA) guidelines. Controls were 115 agesex-residence-matched children who did not have physician-diagnosed asthma. The presence of anti-Toxocara immunoglobulin $\mathrm{G}(\mathrm{IgG})$ was tested using enzyme-linked immunosorbent assay. Univariate and multivariate logistic regression methods were used for case-control comparisons. Results: Seropositivity rate was $4.1 \%(95 \% \mathrm{Cl}, 3.4-4.7 \%)$ in asthmatic children and $0.86 \%(95 \%$ $\mathrm{Cl}, 0.71-1.0 \%)$ in controls, suggesting a strong association ( $P$-value $<0.02)$. Moreover, Toxocara infection was not significantly more prevalent $(P$-value $=0.12)$ in children with moderate sustainable asthma $(9.3 \%, 3 / 32)$ than in children with mild sustainable asthma $(2.3 \%, 3 / 113)$. Mean total immunoglobulin E (IgE) level was significantly higher in Toxocara-infected children (222.3 \pm $367.1)$ than in non-infected children $(143.19 \pm 218.05)$ in the case group ( $P$-value $<0.05)$.

Conclusions: Our findings indicated that Toxocara infection can play an important role in childhood asthma. Further experimental and epidemiological studies are needed to clarify this hypothesis.
\end{abstract}

(c) 2021 Codon Publications. Published by Codon Publications.

*Corresponding author: Ali Rostami. Infectious Diseases and Tropical Medicine Research Center, Health Research Institute, Babol University of Medical Sciences, Babol, Iran. Email address: a.rostami@mubabol.ac.ir; alirostami1984@gmail.com 


\section{Introduction}

Toxocariasis, a worldwide distributed human parasitic disease, is caused by two species of nematode worms from ascaridoid family, Toxocara canis and Toxocara cati., ${ }^{1,2}$ These parasites are common intestinal worms of canine and feline. ${ }^{3,4}$ Humans are paratenic hosts and infection occurs accidentally by the ingestion of infective eggs or, less frequently by contaminated meats containing infective larvae. ${ }^{5,6}$ Although the majority of human cases of toxocariasis are asymptomatic, larval migration to the liver, lungs, brain, and other organ systems can result in several syndromes known as visceral larva migrans (VLM), ocular larva migrans (OLM), neurotoxocariasis (NT), and covert or common toxocariasis. ${ }^{5,7}$ Additionally, in recent years, a growing body of investigations have suggested that human toxocariasis could be a potential risk factor to the development of allergic disorders, such as asthma, atopy, rhinitis, urticaria, and eczema. ${ }^{5,8-10}$

Asthma is a common inflammatory allergic disease affecting around 300 million people worldwide. In 2017, it was estimated that globally, asthma could be responsible for 4,95,100 deaths and about 23 million disability-adjusted life-years. ${ }^{11,12}$ At the global level, almost one in 10 children and one in 12 adults is affected by asthma, and the disease is the cause of a very huge annual healthcare expenditure..$^{13}$ Two forms of asthma (allergic and non-allergic) have usually been defined in the clinic, and children are frequently affected by allergic asthma. ${ }^{13}$ The exact causes of childhood asthma are not well defined, although it is indicated that both genetic (e.g., family atopic history) and environmental factors (e.g., parental smoking, indoor and outdoor allergens, air pollution and infections) are involved in the onset of childhood asthma. Moreover, some evidence from experimental and clinical studies suggests that Toxocara infection can promote the onset of allergic diseases such as asthma. ${ }^{14-16}$

Mazandaran province located in the north of Iran is an endemic area for many zoonotic parasites. ${ }^{17-19}$ A recent study showed that approximately $13 \%$ of children in this area are seropositive for Toxocara infection. ${ }^{20} \mathrm{~A}$ previous study also showed about $4 \%$ of children in this area to be affected by asthma symptoms. ${ }^{21}$ To our knowledge, there has been no study to evaluate the association between Toxocara infection and childhood asthma in this area. Therefore, we designed the present study to assess this association and also to determine the possible risk factors for Toxocara infection in this area.

\section{Ethical approval}

All procedures performed in this study were in accordance with the ethical standards of the institutional and/or national research committee and with the 1964 Declaration of Helsinki and its later amendments or comparable ethical standards.

\section{Informed consent}

Informed consent was obtained from all individual participant's parents included in the study.

\section{Methods}

In this case-control study, we recruited 145 asthmatic children (55.2\% male, mean age $6.88 \pm 2.58$ years) and 115 healthy controls $(56.5 \%$ male, mean age $6.62 \pm$ 3.63 years) referred to the asthma and allergy clinic at Amirkola Hospital, the largest referral pediatric hospital in Mazandaran province, north of Iran. ${ }^{22}$ The study protocol was approved by the Research Ethics Committee of the Babol University of Medical Science, Babol, Iran (no. IR.MUBABOL.HRI.REC.1396.207). Asthmatic children (cases) were recruited according to the following inclusion criteria: physician-diagnosed asthma based on Global Initiative for Asthma (GINA) criteria, ${ }^{23}$ age 2-15 years, and designed consent form was filled in by their parents or legal guardian. Control subjects were non-asthmatic children with the same criteria as the case patients. Children were excluded if they had used anti-parasitic drugs in the past 6 months, or had known clinical symptoms related to toxocariasis such as hepatosplenomegaly, generalized lymphadenopathy, and ocular symptoms. Further details about participation and inclusion and exclusion criteria have been presented in our previous publication. ${ }^{22}$ The parents were asked to complete a questionnaire containing questions about risk factors for asthma, including family atopic history, parents smoking in the home, the child's contacts with pets, and annual family income; and also risk factors for Toxocara infection, including dog or cat ownership, contact with soil, use of unwashed vegetables, use of undercooked meat, and drinking of unsafe water.

For each participant, a venous blood sample of $5 \mathrm{~mL}$ was drawn through venipuncture. Blood samples were centrifuged at $2500 \mathrm{rpm}$ for $15 \mathrm{~min}$. Sera were separated in sterile tubes and were then transported in ice to the laboratory of the Infectious Diseases and Tropical Medicine Research Center at Babol University of Medical Sciences, where they were stored at $-20 \square C$ until use. All collected sera were examined for anti-Toxocara immunoglobulin $G$ (IgG) antibodies using a commercial ELISA kit (NovaTec Immunodiagnostics, Dietzenbach, Germany). The sensitivity and specificity of this kit was more than 95\%. All procedures were performed as per the manufacturer's instructions. The serological examiner was blind to the child's asthma status and about controls. We considered samples of $<9.0$, 9-11, and $>11.0 \mathrm{IU} / \mathrm{mL}$ as negative, suspicious, and positive, respectively, as recommended by the manufacturer.

Statistical analyses were performed using SPSS Statistics software, version 21 (IBM, Armonk, NY, USA). The seroprevalence of Toxocara infection in each group is described as the relative percentage with an exact binomial 95\% confidence interval $(\mathrm{Cl})$. The univariate analyses and multivariate model by Penalized Logistic Regression (PLR) method were used to calculate the Odds ratios (ORs) and 95\% confidence intervals $(95 \% \mathrm{Cls})$ for the association between asthma and Toxocara infection and also to identify the asthma risk factors and Toxocara infection risk factors. A $P$-value $<0.05$ was considered statistically significant.

\section{Results}

The main socio-demographic features of asthmatic and healthy children are presented in Table 1 . The overall 
seroprevalence of Toxocara infection in the study participants was $2.7 \%(95 \% \mathrm{Cl}, 2.4-2.9 \%$; $7 / 260)$ with a seropositivity rate of $4.1 \%(95 \% \mathrm{Cl}, 3.4-4.7 \% ; 6 / 145)$ in asthmatic children and $0.86 \%(95 \% \mathrm{Cl}, 0.71-1.0 \% ; 1 / 115)$ in healthy controls.
Adjusted ORs determined through univariate and multivariate analyses for asthma risk factors were also presented in our previous publication. ${ }^{22}$ In this study, we also include three further items (family atopic history, eating unwashed vegetable, and water source) in multivariate

Table 1 Demographic characteristics of participants and multivariate analyses of asthma risk factors among case-patients and controls.

\begin{tabular}{|c|c|c|c|c|c|c|}
\hline \multirow[t]{2}{*}{ Variable } & \multicolumn{2}{|c|}{$\begin{array}{l}\text { Children with asthma } \\
\qquad(\mathrm{n}=145)\end{array}$} & \multicolumn{2}{|c|}{$\begin{array}{l}\text { Children without asthma } \\
\qquad(\mathrm{n}=115)\end{array}$} & \multirow[t]{2}{*}{$\begin{array}{l}\text { Adjusted OR } \\
\qquad(95 \% \mathrm{Cl})\end{array}$} & \multirow[t]{2}{*}{ P-value } \\
\hline & $\mathrm{N}$ & $\%$ & $\mathrm{~N}$ & $\%$ & & \\
\hline \multicolumn{7}{|l|}{ Sex } \\
\hline Male & 80 & $(55.2)$ & 65 & $(56.5)$ & 1 & 0.951 \\
\hline Female & 65 & $(44.8)$ & 50 & $(43.5)$ & $0.9(0.4-2.2)$ & \\
\hline \multicolumn{7}{|l|}{ Age } \\
\hline$\leq 6$ & 73 & $(50.3)$ & 59 & $(51.3)$ & 1 & \\
\hline $7-12$ & 70 & $(48.3)$ & 48 & $(41.7)$ & $1.1(0.5-2.7)$ & 0.69 \\
\hline $13-18$ & 2 & $(1.4)$ & 8 & $(7.0)$ & $0.7(0.1-5.1)$ & 0.78 \\
\hline \multicolumn{7}{|l|}{ Residence } \\
\hline Urban & 99 & $(68.3)$ & 60 & $(52.2)$ & 1 & \\
\hline Rural & 46 & (31.7) & 55 & $(47.8)$ & $0.3(0.1-0.9)$ & 0.04 \\
\hline \multicolumn{7}{|l|}{ Family income } \\
\hline$\geq 1,500,000 \mathrm{~T}$ & 58 & $(40.0)$ & 32 & $(27.8)$ & $1.06(0.44-2.5)$ & 0.89 \\
\hline$<1,500,000 \mathrm{~T}$ & 87 & $(60.0)$ & 83 & $(72.2)$ & 1 & \\
\hline \multicolumn{7}{|l|}{ Dog contact } \\
\hline Yes & 8 & $(5.5)$ & 14 & $(12.2)$ & $0.08(0.01-0.69)$ & 0.02 \\
\hline No & 137 & $(94.5)$ & 101 & $(87.8)$ & 1 & \\
\hline \multicolumn{7}{|l|}{ Cat contact } \\
\hline Yes & 2 & $(1.4)$ & 3 & $(2.6)$ & $0.69(0.3-144.5)$ & 0.2 \\
\hline No & 143 & $(98.6)$ & 112 & $(97.4)$ & 1 & \\
\hline \multicolumn{7}{|l|}{ Soil contact } \\
\hline Yes & 20 & $(13.8)$ & 14 & $(12.2)$ & $0.5(0.1-2.2)$ & 0.3 \\
\hline No & 125 & $(86.2)$ & 101 & $(87.8)$ & 1 & \\
\hline \multicolumn{7}{|l|}{ Eating unwashed vegetables } \\
\hline Yes & 11 & $(7.6)$ & 6 & $(5.2)$ & $2.9(0.5-16.3)$ & 0.2 \\
\hline No & 134 & $(92.4)$ & 109 & $(94.8)$ & 1 & \\
\hline \multicolumn{7}{|l|}{ Parents education } \\
\hline Illiterate & 2 & $(1.4)$ & 2 & $(1.7)$ & $0.95(0.07-13.3)$ & \\
\hline Primary school & 9 & $(6.2)$ & 23 & $(20.0)$ & $0.05(0.01-0.3)$ & \\
\hline High school & 69 & $(47.6)$ & 68 & $(59.1)$ & $0.4(1.9-0.9)$ & \\
\hline College and above & 65 & $(44.8)$ & 22 & $(19.1)$ & 1 & \\
\hline \multicolumn{7}{|l|}{ Mother's occupation } \\
\hline Housewife & 119 & $(82.1)$ & 107 & $(93.0)$ & $0.6(0.3-1.2)$ & 0.2 \\
\hline Government employment & 26 & $(17.9)$ & 8 & $(7.0)$ & 1 & \\
\hline \multicolumn{7}{|l|}{ Father's occupation } \\
\hline Government employment & 143 & $(98.6)$ & 105 & $(91.3)$ & $0.08(0.01-1.4)$ & 0.08 \\
\hline Farmer & 2 & $(1.4)$ & 10 & $(8.7)$ & 1 & \\
\hline \multicolumn{7}{|l|}{ Water source } \\
\hline Treated & 79 & $(54.5)$ & 103 & $(89.6)$ & 1 & \\
\hline Untreated & 66 & $(45.5)$ & 12 & $(10.4)$ & $20.1(6.2-65.3)$ & $<0.001$ \\
\hline \multicolumn{7}{|l|}{ Family atopic history } \\
\hline Yes & 85 & $(58.6)$ & 5 & $(4.3)$ & $42.5(13.0-138.6)$ & $<0.001$ \\
\hline No & 60 & $(41.4)$ & 110 & $(95.7)$ & 1 & \\
\hline \multicolumn{7}{|l|}{ Toxocara infection } \\
\hline Yes & 6 & $(4.1)$ & 1 & $(0.9)$ & 52.7 (1.7-1578.5) & 0.02 \\
\hline No & 139 & $(95.9)$ & 114 & $(99.1)$ & 1 & \\
\hline
\end{tabular}


analysis. In new analyses, the multivariate analyses identified that older children (age more than 12 years) had a non-significant lower risk to be asthmatic (OR, 0.77; 95\% $\mathrm{Cl}, 0.11-5.1 ; P$-value $=0.78$ ), although living in rural areas (OR, 0.37; 95\% Cl, 0.14-0.97; $P$-value $=0.04)$, contact with dog (OR, 0.08; 95\% Cl, 0.01-0.69; $P$-value $=0.02)$, and having parents with higher levels of education (OR, $0.4 ; 95 \%$ $\mathrm{Cl}$, 0.16-0.99; $P$-value $=0.04$ ) were significant protective factors for childhood asthma. In comparison with healthy children, case-patients were more likely to have an atopic history in the family $(\mathrm{OR}, 42.5 ; 95 \% \mathrm{Cl}, 13.0-138.6 ; P$-value $<0.001)$, and usage of untreated water $(\mathrm{OR}, 20.1 ; 95 \% \mathrm{Cl}$, 6.2-65.3). No significant association was found between asthma status and contact with cats. The unadjusted and adjusted ORs for the association between asthma and Toxocara infection were $(\mathrm{OR}, 4.9 ; 95 \% \mathrm{Cl}, 0.58-41.4)$ and (OR, 52.7; 95\% Cl, 1.7- 1578.5), respectively, suggesting a significant positive association ( $P$-value $<0.001)$. Mean total immunoglobulin $\mathrm{E}$ (IgE) was significantly higher in Toxocara-infected children $(222.3 \pm 367.1)$ than in non-infected children $(143.19 \pm 218.05)$ in the case group ( $P$-value $<0.05)$. Moreover, Toxocara infection was non-significantly more prevalent $(\mathrm{OR}, 3.79 ; 95 \% \mathrm{Cl}, 0.73-19.7 ; P$-value $=$ 0.12 ) in children with moderate sustainable asthma $(9.3 \%$; $3 / 32)$ than in children with mild sustainable asthma $(2.3 \%$, 3/113).

Table 2 gives the unadjusted and adjusted ORs for potential risk factors of Toxocara infection. According to univariate analyses, children who were seropositive for Toxocara were more likely to have contact with dogs (OR, 34.7; 95\% Cl, 6.2-192.2), cats (OR, 10.7; 95\% Cl, 1.0-107.2), and soil (OR, 123.5; 95\% Cl, 6.8-2222.8) and also more likely to consume unwashed vegetables $(\mathrm{OR}, 6.3 ; 95 \% \mathrm{Cl}, 1.1$ 35.4). However, contact with dog and soil were only potential risk factors for Toxocara infection in the multivariate analysis (Table 2).

\section{Discussion}

We performed this case-control study to clarify whether there is an association between Toxocara infection and childhood asthma. Our main reason for performing this study was the fact that both Toxocara infection and asthma are widely distributed in northern Iran and some previous experimental and epidemiological studies have suggested that Toxocara infection can play an etiological role in the development of asthma and other allergic disorders. The present epidemiologic study provides support for the association between Toxocara infection and childhood asthma, and the association was strong after controlling for confounders. Moreover, our results showed more severe asthma and more total IgE level in asthmatic children with Toxocara infection compared with non-infected children.

To the best of our knowledge, the role of Toxocara infection in the development of allergic disorders is controversial. The results of our multivariate analysis, when other confounders were adjusted, showed a strong association between Toxocara infection and childhood asthma. In agreement with our results, some previous epidemiologic studies showed a significant association related to
Toxocara infection and childhood asthma, ${ }^{24-30}$ although others showed a non-significant association. ${ }^{31-37}$ An explanation for these different results could be a difference in the age of the study population, study design, different ethnic populations, genetic, geographical area, and different sensitivity and specificity of diagnostic methods (in-house or commercial ELISA and Western blot). Moreover, a recent meta-analysis indicated a significant positive association between exposure to Toxocara infection and increased risk of childhood asthma (OR, 1.91; 95\% Cl, 1.47-52.47). This association was also persistent in sub-group analysis for both case-control (OR, 2.13; 95\% Cl, 1.43-3.15) and cross-sectional (OR, 1.73; 95\% Cl, 1.23-2.44) studies.

Although the underlying pathomechanism is not well established, it seems that somatic migration of Toxocara larvae to different organs including lung and intensive human immunological responses to these larvae are the main effectors to the development of asthma. ${ }^{8,10}$ In line with this statement, some experimental studies indicated persistent airway hyperresponsiveness, airway inflammation, and diminished lung function in mice following infection with Toxocara larvae. ${ }^{16,38}$ It has been shown that pulmonary inflammation occurs 48 -h post-infection and can continue for up to 3 months. ${ }^{38}$ Other possible mechanisms are an increase in specific IgE against Toxocara antigens that can bind to high-affinity IgE receptors (FcERI) on mast cells and lead to degranulation of mast cells and the release of vasoactive substances like histamine..$^{8,39}$ In line with this statement, our results showed levels of total IgE in Toxocara-infected children which were significantly higher than in non-infected children. Moreover, Pinelli et al., ${ }^{16}$ in an experimental study, indicated that Toxocara infection elevated levels of IgE antibody and eosinophil counts in bronchoalveolar lavage fluid, and also the expression of IL-4 mRNA in lung tissue of infected mice.

With respect to risk factors for Toxocara infection, we have found that contact with dogs, cats and soil, and also eating unwashed vegetables were potential risk factors in univariate and multivariate analyses. This is in agreement with the results from our previous study among the general population in northern Iran. ${ }^{20}$ Moreover, a recent comprehensive meta-analysis evaluating the global prevalence of Toxocara infection showed that male gender, living in a rural area, young age, close contact with dogs, cats or soil, consumption of raw meat, and the drinking of untreated water were significant potential risk factors for the acquisition of Toxocara infection. ${ }^{40}$

This study has some limitations and the results presented here should be interpreted with regard to these limitations. The major limitation of this study is our low sample size with a low number of seropositive children in both the case and control groups that caused some problems in our statistical analysis. For example, although we used the PLR method to resolve this limitation, large OR and $95 \% \mathrm{Cls}$ were some of the observed variables. Another limitation was that we were unable to perform Western blot examination on sera samples and also there are no supporting data on blood eosinophils or complete blood count $(C B C)$. The final limitation is related to cross-reaction of IgG-ELISA kit with other helminth infections such as ascariasis, trichinellosis, filariasis, etc. Also, according to 
Table 2 Univariate and multivariate analyses of risk factors associated with Toxocara infection among children in northern Iran.

\begin{tabular}{|c|c|c|c|c|}
\hline \multirow[t]{2}{*}{ Variable } & \multicolumn{2}{|c|}{ All children $(n=260)$} & \multirow{2}{*}{$\begin{array}{c}\text { Univariate OR } \\
(95 \% \mathrm{Cl})\end{array}$} & \multirow{2}{*}{$\begin{array}{c}\text { Multivariate } \\
\text { OR }(95 \% \mathrm{CI})\end{array}$} \\
\hline & $\mathrm{N}$ & $\%$ & & \\
\hline \multicolumn{5}{|l|}{ Sex } \\
\hline Male & 145 & $4(2.8)$ & 1 & 1 \\
\hline Female & 115 & $3(2.6)$ & $0.94(0.21-4.31)$ & $2.08(0.10-273.31)$ \\
\hline \multicolumn{5}{|l|}{ Age } \\
\hline$\leq 6$ & 132 & $5(3.8)$ & 1 & 1 \\
\hline $7-12$ & 118 & $2(2.7)$ & $0.44(0.08-2.30)$ & $0.01(0.00-0.72)$ \\
\hline $13-18$ & 10 & 0.0 & $1.10(0.06-21.36)$ & $0.06(0.00-28.49)$ \\
\hline \multicolumn{5}{|l|}{ Residence } \\
\hline Rural & 101 & $2(2.0)$ & $0.62(0.12-3.27)$ & $0.01(0.00-1.22)$ \\
\hline Urban & 159 & $5(3.1)$ & 1 & 1 \\
\hline \multicolumn{5}{|l|}{ Family income } \\
\hline$<1,500,000 \mathrm{~T}$ & 170 & $6(3.5)$ & $3.26(0.39-27.47)$ & $1.26(0.01-2770.24)$ \\
\hline$\geq 1,500,000 \mathrm{~T}$ & 90 & $1(1.1)$ & 1 & 1 \\
\hline \multicolumn{5}{|l|}{ Dog contact } \\
\hline Yes & 22 & $5(22.7)$ & $34.71(6.26-192.29)^{*}$ & $41.61(2.54-26470.70)^{*}$ \\
\hline No & 238 & $2(0.8)$ & 1 & 1 \\
\hline \multicolumn{5}{|l|}{ Cat contact } \\
\hline Yes & 5 & $1(20.0)$ & $10.37(1.00-107.29)^{*}$ & $3.07(0.01-1333.67)$ \\
\hline No & 255 & $6(2.4)$ & 1 & 1 \\
\hline \multicolumn{5}{|l|}{ Soil contact } \\
\hline Yes & 34 & $7(20.6)$ & $\begin{array}{c}123.55 \\
(6.87-2222.86)^{*}\end{array}$ & $297.47(4.92-16069861)^{*}$ \\
\hline No & 126 & $0(0.0)$ & 1 & 1 \\
\hline \multicolumn{5}{|c|}{ Eating unwashed vegetables } \\
\hline Yes & 17 & $2(11.8)$ & $6.35(1.14-35.47)^{*}$ & $1.33(0.01-91.96)$ \\
\hline No & 243 & $5(2.1)$ & 1 & 1 \\
\hline \multicolumn{5}{|l|}{ Parents education } \\
\hline Illiterate & 4 & $0(0.0)$ & $2.68(0.12-60.22)$ & $5.14(0.02-8777.06)$ \\
\hline Primary school & 32 & $1(3.1)$ & $0.90(0.09-9.01)$ & $0.16(0.00-103.64)$ \\
\hline High school & 137 & $3(2.2)$ & $0.63(0.12-3.18)$ & $1.31(0.03-584.26)$ \\
\hline College and above & 87 & $3(3.4)$ & 1 & 1 \\
\hline \multicolumn{5}{|l|}{ Water source } \\
\hline Untreated & 78 & $1(1.3)$ & $2.63(0.31-22.17)$ & $1.91(0.05-66.60)$ \\
\hline Treated & 182 & $6(3.3)$ & 1 & 1 \\
\hline
\end{tabular}

*Statistically significant $(P$-value $<0.01)$.

our experience in previous studies, the NovaTec kit has not shown cross-reactivity with ascariasis. ${ }^{20,22}$

In conclusion and notwithstanding the abovementioned limitations, the results of the present study provide strong evidence that Toxocara infection may be associated with childhood asthma. More longitudinal epidemiologic and experimental studies are needed to further explore the role of Toxocara infection in the development of childhood asthma and also to elucidate the immunological and molecular mechanisms that underpin this association. Furthermore, according to our findings about risk factors of Toxocara infection in the studied area, personal health education and applying the preventive measures to avoid exposure to Toxocara infection in children seems necessary in the studied area.

\section{Acknowledgments}

The authors are very thankful to the staff of the Amirkola Hospital of Babol University of Medical Sciences, especially Dr. Esmaeili Dooki, Dr. Javanian, and Dr. Pournasrollah, for their kind assistance in this study. Most importantly, the authors would like to thank all the participants in this study.

\section{Funding}

This work was supported by Institute Health Research at the Babol University of Medical Sciences (Grant number IR.MUBABOL. HRI.REC.1396.207). 


\section{Conflict of interest}

None of the authors have any conflict of interest.

\section{References}

1. Fakhri Y, Gasser R, Rostami A, Fan C, Ghasemi S, Javanian M, et al. Toxocara eggs in public places worldwide - a systematic review and meta-analysis. Environ Pollut. 2018;242:1467-1475. https://doi.org/10.1016/j.envpol.2018.07.087

2. Ma G, Holland CV, Wang T, Hofmann A, Fan C-K, Maizels RM, et al. Human toxocariasis. Lancet Infect Dis. 2018;18(1): e14-e24. https://doi.org/10.1016/S1473-3099(17)30331-6

3. Rostami A, Sepidarkish M, Ma G, Wang T, Ebrahimi M, Fakhri Y, et al. Global prevalence of Toxocara infection in cats. Adv Parasitol. 2020;109:615-639. https://doi.org/10.1016/ bs.apar.2020.01.025

4. Rostami A, Riahi SM, Hofmann A, Ma G, Wang T, Behniafar H, et al. Global prevalence of Toxocara infection in dogs. Adv Parasitol. 2020;109:561-583. https://doi.org/10.1016/ bs.apar.2020.01.017

5. Rostami A, Ma G, Wang T, Koehler AV, Hofmann A, Chang $B C$, et al. Human toxocariasis - a look at a neglected disease through an epidemiological 'prism'. Infect Genet Evol. 2019:74;104002. https://doi.org/10.1016/j. meegid.2019.104002

6. Rostami A, Riahi SM, Fallah Omrani V, Wang T, Hofmann A, Mirzapour A, et al. Global prevalence estimates of Toxascaris leonina infection in dogs and cats. Pathogens. 2020;9(6):503. https://doi.org/10.3390/pathogens 9060503

7. Ma G, Rostami A, Wang T, Hofmann A, Hotez PJ, Gasser RB. Global and regional seroprevalence estimates for human toxocariasis: a call for action. Adv Parasitol. 2020;109:275-290. https://doi.org/10.1016/bs.apar.2020.01.011

8. Mohammadzadeh I, Riahi SM, Saber V, Darvish S, Amrovani M, Arefkhah N, et al. The relationship between Toxocara species seropositivity and allergic skin disorders: a systematic review and meta-analysis. Trans $\mathrm{R}$ Soc Trop Med Hyg. 2018;112(12):529-537. https://doi.org/10.1093/trstmh/try094

9. Baghani Z, Khazan H, Sohrabi MR, Rostami A. Seroprevalence of Toxocara infection among healthy individuals referred to the medical center laboratories in Tehran City, Capital of Iran. Novel Biomed. 2018;6(2):68-73. https://doi.org/10.22037/nbm. v6i2.16938

10. Fischer N, Rostaher A, Zwickl L, Deplazes P, Olivry T, Favrot C. A Toxocara canis infection influences the immune response to house dust mite allergens in dogs. Vet Immunol Immunopathol. 2018;202:11-7. https://doi.org/10.1016/j. vetimm.2018.06.009

11. Roth GA, Abate D, Abate KH, Abay SM, Abbafati C, Abbasi N, et al. Global, regional, and national age-sex-specific mortality for 282 causes of death in 195 countries and territories, 19802017: a systematic analysis for the Global Burden of Disease Study 2017. Lancet. 2018;392(10159):1736-1788. https://doi. org/10.1016/S0140-6736(18)32203-7

12. Kyu HH, Abate D, Abate $\mathrm{KH}$, Abay SM, Abbafati C, Abbasi $\mathrm{N}$, et al. Global, regional, and national disability-adjusted lifeyears (DALYs) for 359 diseases and injuries and healthy life expectancy (HALE) for 195 countries and territories, 19902017: a systematic analysis for the Global Burden of Disease Study 2017. Lancet. 2018;392(10159):1859-1922. https://doi. org/10.1016/S0140-6736(18)32335-3

13. Lambrecht BN, Hammad $H$. The immunology of asthma. Nat Immunol. 2015;16(1):45. https://doi.org/10.1038/ni.3049

14. Aghaei S, Riahi SM, Rostami A, Mohammadzadeh I, Javanian M, Tohidi E, et al. Toxocara spp. infection and risk of childhood asthma: a systematic review and meta-analysis. Acta Trop. 2018;182:298-304. https://doi.org/10.1016/j.actatropica. 2018.03.022

15. Cooper P. Toxocara canis infection: an important and neglected environmental risk factor for asthma? [This editorial discusses the findings of the paper in this issue by $\mathrm{E}$. Pinelli et al. [19], pp 649-658.] Clin Exp Allergy. 2008;38(4):551-553. https://doi.org/10.1111/j.1365-2222.2008.02934.x

16. Pinelli E, Brandes S, Dormans J, Gremmer E, Van Loveren H. Infection with the roundworm Toxocara canis leads to exacerbation of experimental allergic airway inflammation. Clin Exp Allergy. 2008;38(4):649-658. https://doi. org/10.1111/j.1365-2222.2007.02908.x

17. Rostami A, Seyyedtabaei SJ, Aghamolaie S, Behniafar $H$, Lasjerdi Z, Abdolrasouli A, et al. Seroprevalence and risk factors associated with Toxoplasma gondii infection among rural communities in northern Iran. Rev Inst Med Trop Sao Paulo. 2016;58:70. https://doi.org/10.1590/S1678-9946201658070

18. Rostami A, Mozafari M, Gholipourmalekabadi M, Caicedo HH, Lasjerdi Z, Sameni M, et al. Optimization of fluoride-containing bioactive glasses as a novel scolicidal agent adjunct to hydatid surgery. Acta Trop. 2015;148:105-114. https://doi. org/10.1016/j.actatropica.2015.04.021

19. Siyadatpanah A, Tabatabaei F, Zeydi AE, Spotin A, FallahOmrani V, Assadi $M$, et al. Parasitic contamination of raw vegetables in Amol, North of Iran. Arch Clin Infect Dis. 2013;8(2):e15983. https://doi.org/10.5812/archcid.15983

20. Aghamolaie S, Seyyedtabaei SJ, Behniafar $H$, et al. Seroepidemiology, modifiable risk factors and clinical symptoms of Toxocara spp. infection in northern Iran. Trans R Soc Trop Med Hyg. 2019;113:116-122. https://doi.org/10.1093/ trstmh/try118

21. Mohammadzadeh I, Ghafari J, Savadkoohi RB, Tamaddoni A, Dooki MRE, Navaei RA. The prevalence of asthma, allergic rhinitis and eczema in north of Iran. Iran J Pediatr. 2008;18(2):117-122.

22. Mohammadzadeh I, Rostami A, Darvish S, Mehravar S, Pournasrollah M, Javanian M, et al. Exposure to Ascaris lumbricoides infection and risk of childhood asthma in north of Iran. Infection. 2019: 47(6):991-999. https://doi.org/10.1007/ s15010-019-01343-0.

23. Becker AB, Abrams EM. Asthma guidelines: the Global Initiative for Asthma in relation to national guidelines. Curr Opin Allergy Clin Immunol. 2017;17(2):99-103. https://doi. org/10.1097/ACl.0000000000000346

24. Buijs J, Borsboom G, van Gemund JJ, et al. Toxocara seroprevalence in 5-year-old elementary schoolchildren: relation with allergic asthma. Am J Epidemiol. 1994;140(9):839-847. https://doi.org/10.1093/oxfordjournals.aje.a117332

25. Buijs J, Borsboom G, van Gemund JJ, Hazebroek A, van Dongen PA, van Knapen F, et al. Relationship between allergic manifestations and Toxocara seropositivity: a cross-sectional study among elementary school children. Eur Respir J. 199710(7): 1467-1475. https://doi.org/10.1183/09031936.97.10071467

26. Cobzaru R-G, Rîpă C, Leon MM, Luca MC, Ivan A, Luca M. Correlation between asthma and Toxocara canis infection. Rev Med Chir Soc Med Nat lasi. 2012;116(3):727-730.

27. Fernando D, Wickramasinghe $P$, Kapilananda G, Dewasurendra RL, Amarasooriya M, Dayaratne A. Toxocara seropositivity in Sri Lankan children with asthma. Pediatr Int. 2009;51(2):241-245. https://doi.org/10.1111/j.1442-200X.2008.02687.X

28. Hakim SL, Thadasavanth M, Shamilah RR, Yogeswari S. Prevalence of Toxocara canis antibody among children with bronchial asthma in Klang Hospital, Malaysia. Trans R Soc Trop Med Hyg. 1997;91(5):528. https://doi.org/10.1016/ S0035-9203(97)90010-9

29. Kanobana K, Vereecken K, Junco Diaz R, Sariego I, Rojas L, Bonet Gorbea M, et al. Toxocara seropositivity, atopy and 
asthma: a study in Cuban schoolchildren. Trop Med Int Health. 2013;18(4):403-406. https://doi.org/10.1111/tmi.12073

30. Muñoz-Guzmán M, del Río-Navarro BE, Valdivia-Anda G, AlbaHurtado $F$. The increase in seroprevalence to Toxocara canis in asthmatic children is related to cross-reaction with Ascaris suum antigens. Allergol Immunopathol. 2010;38(3):115-121. https://doi.org/10.1016/j.aller.2009.09.007

31. Cadore PS, Zhang L, Lemos LdL, Lorenzi C, Telmo PdL, dos Santos PC, et al. Toxocariasis and childhood asthma: a case-control study. J Asthma. 2016;53(6):601-606. https://doi. org/10.3109/02770903.2015.1064951

32. Chan PW, Anuar AK, Fong MY, Debruyne JA, Ibrahim J. Toxocara seroprevalence and childhood asthma among Malaysian children. Pediatr Int. 2001;43(4):350-353. https:// doi.org/10.1046/j.1442-200X.2001.01421.X

33. Figueiredo SD, Taddei JA, Menezes JJ, Novo NF, Silva EO, Cristóvão $\mathrm{HL}$, et al. Clinical-epidemiological study of toxocariasis in a pediatric population. J Pediatr. 2005;81(2):126-132. https://doi.org/10.1590/S0021-75572005000300007 https:// doi.org/10.2223/JPED.1317 https://doi.org/10.2223/1317

34. Mendonça LR, Veiga RV, Dattoli VCC, Figueiredo CA, Fiaccone R, Santos J, et al. Toxocara seropositivity, atopy and wheezing in children living in poor neighbourhoods in urban Latin American. PLoS Negl Trop Dis. 2012;6(11):e1886. https:// doi.org/10.1371/journal.pntd.0001886

35. Mosayebi M, Moini L, Hajihossein R, Didehdar M, Eslamirad Z. Detection of specific antibody reactivity to Toxocara larval excretory-secretory antigens in asthmatic patients
(5-15 years). Open Microbiol J. 2016;10:162. https://doi. org/10.2174/1874285801610010162

36. Sharghi N, Schantz PM, Caramico L, Ballas K, Teague BA, Hotez PJ. Environmental exposure to Toxocara as a possible risk factor for asthma: a clinic-based case-control study. Clin Infect Dis. 2001;32(7):e111-e116.https://doi. org/10.1086/319593

37. Silva MB, Amor AL, Santos LN, Galvão AA, Vera AVO, Silva ES, et al. Risk factors for Toxocara spp. seroprevalence and its association with atopy and asthma phenotypes in school-age children in a small town and semi- rural areas of Northeast Brazil. Acta Trop. 2017;174:158-164. https://doi.org/10.1016/j. actatropica.2016.04.005

38. Pinelli E, Withagen C, Fonville M, Verlaan A, Dormans J, Van Loveren $\mathrm{H}$, et al. Persistent airway hyper-responsiveness and inflammation in Toxocara canis-infected BALB/C mice. Clin Exp Allergy. 2005;35(6):826-832. https://doi.org/ 10.1111/j.1365-2222.2005.02250.x

39. Carlos D, Sá-Nunes A, de Paula L, Matias-Peres C, Jamur MC, Oliver $C$, et al. Histamine modulates mast cell degranulation through an indirect mechanism in a model IgE-mediated reaction. Eur J Immunol. 2006;36(6):1494-1503. https://doi. org/10.1002/eji.200535464

40. Rostami A, Riahi S, Holland C, Taghipour A, Khalili-Fomeshi M, Fakhri $Y$, et al. Seroprevalence estimates for toxocariasis in people worldwide: a systematic review and meta-analysis. PLoS Negl Trop Dis. 2019;13(12):e0007809. https://doi. org/10.1371/journal.pntd.0007809 